\title{
Factors influencing the outcome of congenital heart disease detected prenatally
}

\author{
Gurleen K Sharland, Susan M Lockhart, Sunder K Chita, Lindsey D Allan
}

\begin{abstract}
The diagnosis of structural heart disease before birth is associated with a poor prognosis. Of 222 continuing pregnancies seen in a 10 year period, there has been a $79 \%$ mortality. This is inconsistent with published results and current concepts of the outcome for children with cardiac malformation. Of the 222 , death occurred in intrauterine life in 57,87 died as neonates, and 31 in infancy or childhood. There are 47 survivors of whom only five have survived beyond 4 years.

Factors influencing the outcome in these cases were examined further. A high mortality was associated with the presence of extracardiac anomalies in $71(32 \%)$ and prenatal cardiac failure in 28 (13\%). As many patients were referred for these reasons, referral methods preferentially select patients with a different range of heart disease from that seen postnatally. In addition, some forms of heart disease progress in severity during fetal life. Those involved in the management and counselling after diagnosis of heart disease in early pregnancy must be aware of the additional prenatal factors influencing prognosis and allow for them in making predictions of outcome.
\end{abstract}
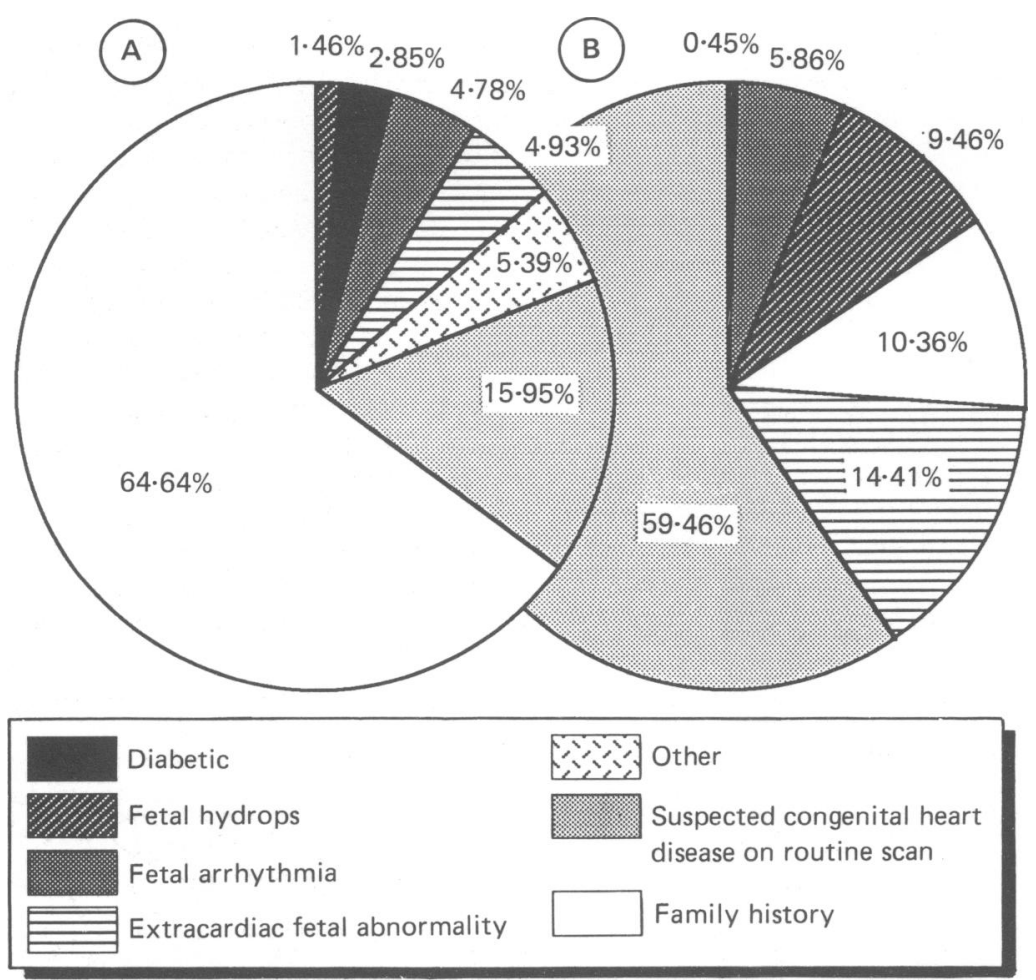

Figure $1(A)$ Reasons for referral in 1298 pregnancies referred for fetal echocardiography in 1989. (B) Reasons for referral in study group of 222 cases of fetal congenital heart disease.
Over the last 10 years fetal echocardiography has become established as an accurate method of predicting structural cardiac malformations prenatally. ${ }^{12}$ There has been a progressive increase in the number of cases referred for fetal echocardiography and a corresponding increase in the number of cases detected prenatally, but the outcome for congenital heart disease diagnosed in utero is poor. One of the main reasons for this is the high rate of termination of pregnancy after the detection of a severe cardiac abnormality. In our series of 442 cases of cardiac malformation diagnosed in utero, approximately $50 \%$ of cases resulted in a termination of pregnancy. Of 222 pregnancies that continued, however, the survival rate is still low with only 47 infants still alive $(21 \%)$. In order to account for the high mortality, associated factors that might influence the outcome were analysed.

\section{Methods}

Between 1980 and the end of 1989 over 7000 high risk pregnancies were referred to our unit for fetal echocardiography. High risk factors include maternal reasons, such as a family history of congenital heart disease, maternal diabetes or exposure to cardiac teratogens in early pregnancy, or fetal indications such as the detection of hydrops, extracardiac anomalies, arrhythmias, or an abnormality of the four chamber view on a routine scan. The proportion of cases seen in each referral group during one year are shown in fig 1A. The gestational age at presentation varied from $16-40$ weeks. A structural malformation of the fetal heart was diagnosed in 442 cases. After the detection of severe congenital heart disease, the pregnancy was electively ended in 220 cases and these cases are excluded from this study. In the remaining 222 cases the pregnancy continued and these form the study group. The referral reason was a suspected cardiac abnormality on four chamber view screening in 132, an extracardiac fetal abnormality in 32 , a family history of congenital heart disease in 23 , the presence of non-immune fetal hydrops in 21 , a suspected fetal arrhythmia in 13, and maternal diabetes in one case. The proportions of referral groups in the abnormal cases are shown in fig 1B. The case records of all the patients were examined retrospectively. Videotape recordings of all the fetal scans were available for inspection. The type of cardiac lesion present in each case was recorded. Evidence of extracardiac structural and chromosomal anomalies seen either on the scan or detected subsequently on postnatal or postmortem examination were recorded for each case. 


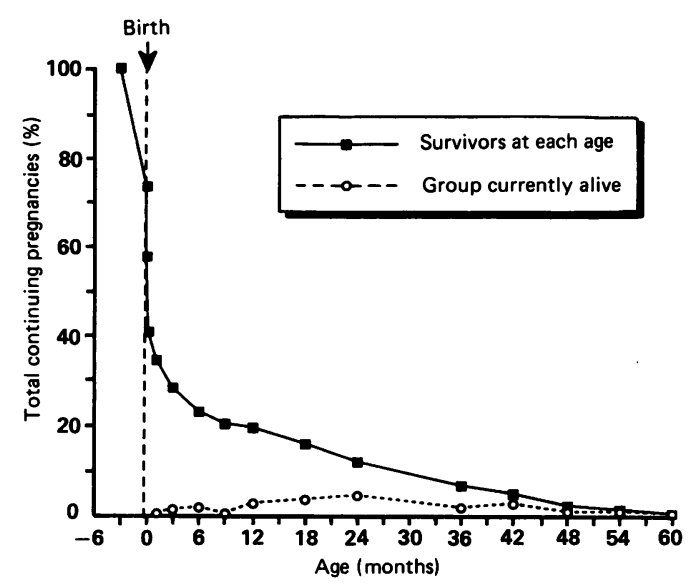

Figure 2 Time of survival after the diagnosis of prenatal congenital heart disease. The bold line shows the length of survival after diagnosis and the interrupted line shows the ages of the 47 cases that are still alive. The survival numbers are represented as a percentage of the total study group (222 cases).

Signs of intrauterine cardiac failure, which include fetal ascites, skin oedema, pleural and pericardial effusions, were sought on each scan.

\section{Results}

Of 222 continuing pregnancies, 57 resulted in a spontaneous intrauterine death. There were, therefore, 165 infants $(74 \%)$ that were born alive and of these, 87 died in the neonatal period, 29 in infancy, and two in childhood. There are 47 cases that are still alive. The length of survival after the prenatal diagnosis of congenital heart disease is shown in fig 2 . Of the 165 infants born alive, 36 died in the first 24 hours of life so that only $129(58 \%)$ survived this period. At 1 week of age, $90(41 \%)$ were still alive and this fell to $78(35 \%)$ at 1 month of age, $51(23 \%)$ at 6 months, $43(19 \%)$ at 1 year, and 26 $(12 \%)$ at 2 years. Of the cases that are now alive, three infants are under 6 months of age, a further 11 are under 1 year, 18 are between 1 and 2 years of age, four between 2 and 3 years, and six between 3 and 4 years. Five cases have survived beyond 4 years, only one of whom is over 5 years.

An extracardiac fetal anomaly was associated in 71 cases $(32 \%)$ of whom $42(19 \%)$ had a chromosomal abnormality. The total incidence of associated anomalies were higher in the group resulting in an intrauterine or neonatal death (39\% and $40 \%$ respectively) compared with the group that died in infancy and the surviving group (20\% and $17 \%$ respectively) (table 1 ). Chromosomal anomalies were present in $21 \%$ of those resulting in an intrauterine death, $24 \%$ of
Table 2 Types of extracardiac structural abnormalities and chromosomal anomalies associated with congenital heart disease in the study group

\begin{tabular}{lcl}
\hline Extracardiac anomaly & Total No & $\begin{array}{l}\text { No with associated } \\
\text { chromosomal anomaly }\end{array}$ \\
\hline Exomphalos & 12 & 5 \\
Diaphragmatic hernia & 7 & 2 \\
Renal & 5 & 1 \\
Duodenal atresia & 5 & 2 \\
Oesophageal atresia & 3 & 0 \\
Anal atresia & 1 & 1 \\
Conjoint twins & 4 & 0 \\
Cystic hygroma & 2 & 2 \\
Multiple & 3 & 0 \\
\hline
\end{tabular}

those resulting in a neonatal death, $13 \%$ of those who died after the neonatal period, and $11 \%$ of those that are still alive. The types of associated extracardiac structural anomalies and chromosomal abnormalities are shown in tables 2 and 3. There was evidence of intrauterine cardiac failure in 28 fetuses (13\%). Of these, 16 resulted in an intrauterine death, 10 resulted in a neonatal death, one case died in infancy, and one child survived. In $10(5 \%)$ there was an extracardiac structural abnormality detected in addition to the cardiac anomaly but in the remaining $18(8 \%)$ there was structural heart disease only. The incidence of fetal hydrops was particularly high (28\%) in the group resulting in a spontaneous intrauterine death compared with the other groups $(11 \%$ in the neonatal death group, $3 \%$ in the infant deaths, and $2 \%$ of the survivors).

A wide range of cardiac malformations were detected in the 222 fetuses and the diagnoses are summarised in table 4 . There were some types of cardiac malformation that were particularly associated with a high mortality. Some of these were expected, for example, cases of the hypoplastic left heart syndrome. Others include cases of tricuspid valve dysplasia and Ebstein's anomaly in whom the mortality in continuing pregnancies was $90 \%$. In cases of critical aortic stenosis detected prenatally the mortality in this series was $100 \%$. Progression of cardiac disease was observed in many of these cases. In six cases with tricuspid valve dysplasia or Ebstein's anomaly, there was progressive cardiomegaly reflected by an increasing fetal cardiothoracic ratio during pregnancy. This type of heart disease is frequently associated with pulmonary artery abnormalities. In two of these cases, pulmonary stenosis progressed to pulmonary atresia during fetal life and in one case pulmonary stenosis developed during fetal life. There was one further case with isolated pulmonary stenosis in whom the initial scan was normal and evidence of pulmonary stenosis developed subsequently. In five cases that had critical aortic ste-

Table 1 Incidence of associated extracardiac and chromosomal anomalies in whole group $(n=222)$ and each of the outcome groups

\begin{tabular}{|c|c|c|c|c|c|}
\hline & \multirow[t]{2}{*}{ Total } & \multicolumn{4}{|l|}{ Outcome } \\
\hline & & $\begin{array}{l}\text { Intrauterine } \\
\text { death } \\
(n=57)\end{array}$ & $\begin{array}{l}\text { Neonatal } \\
\text { death } \\
(n=87)\end{array}$ & $\begin{array}{l}\text { Infant } \\
\text { (childhood) } \\
\text { death } \\
(n=31)\end{array}$ & $\begin{array}{l}\text { Alive } \\
(n=47)\end{array}$ \\
\hline $\begin{array}{l}\text { Extracardiac anomalies } \\
\text { (normal karyotype) } \\
\text { Chromosomal anomalies }\end{array}$ & $\begin{array}{l}29(13) \\
42(19)\end{array}$ & $\begin{array}{l}10(18) \\
12(21)\end{array}$ & $\begin{array}{l}14(16) \\
21(24)\end{array}$ & $\begin{array}{l}2(7) \\
4(13)\end{array}$ & $\begin{array}{l}3(6) \\
5(11)\end{array}$ \\
\hline
\end{tabular}

The percentage of the total study group is indicated (in parentheses) in addition to the percentages of each of the outcome groups. 
Table 3 Types of karyotype anomalies and outcome associated with prenatal congenital heart disease

\begin{tabular}{|c|c|c|c|c|c|}
\hline \multirow{2}{*}{$\begin{array}{l}\text { Chromosomal } \\
\text { anomaly }\end{array}$} & \multirow[t]{2}{*}{ Total } & \multicolumn{4}{|l|}{ Outcome } \\
\hline & & $\begin{array}{l}\text { Intrauterine } \\
\text { death }\end{array}$ & $\begin{array}{l}\text { Neonatal } \\
\text { death }\end{array}$ & $\begin{array}{l}\text { Infant } \\
\text { (childhood) } \\
\text { death }\end{array}$ & Alive \\
\hline $\begin{array}{l}\text { Trisomy } 21 \\
\text { Trisomy } 18 \\
\text { Trisomy } 13 \\
\text { Turner's syndrome (XO) } \\
+9 / 10 \\
13 \mathrm{q}- \\
8 \mathrm{q}- \\
-10 \\
\text { XXY }\end{array}$ & $\begin{array}{r}14 \\
16 \\
5 \\
2 \\
1 \\
1 \\
1 \\
1 \\
1\end{array}$ & $\begin{array}{l}5 \\
3 \\
3 \\
2 \\
0 \\
0 \\
0 \\
0 \\
0\end{array}$ & $\begin{array}{r}3 \\
12 \\
2 \\
0 \\
1 \\
1 \\
1 \\
0 \\
0\end{array}$ & $\begin{array}{l}1 \\
1 \\
0 \\
0 \\
0 \\
0 \\
0 \\
1\end{array}$ & $\begin{array}{l}5 \\
0 \\
0 \\
0 \\
0 \\
0 \\
0 \\
0 \\
0\end{array}$ \\
\hline
\end{tabular}

Table 4 Cardiac malformation and outcome in 222 cases of fetal congenital heart disease

\begin{tabular}{|c|c|c|c|c|}
\hline Diagnosis & $\begin{array}{l}\text { Intrauterine } \\
\text { death }\end{array}$ & $\begin{array}{l}\text { Neonatal } \\
\text { death }\end{array}$ & $\begin{array}{l}\text { Infant } \\
\text { (childhood) } \\
\text { death }\end{array}$ & Alive \\
\hline $\begin{array}{l}\text { Hypoplastic left heart syndrome } \\
\text { Mitral atresia, double outlet right ventricle } \\
\text { Aortic atresia } \\
\text { Critical aortic stenosis } \\
\text { Coarctation } \\
\text { Interrupted aortic arch } \\
\text { Ebstein's anomaly/tricuspid valve dysplasia } \\
\text { Tricuspid atresia } \\
\text { Pulmonary atresia } \\
\text { Tetralogy of Fallot } \\
\text { Absent pulmonary valve } \\
\text { Pulmonary stenosis } \\
\text { Atrioventricular septal defect } \\
\text { Ventricular septal defect } \\
\text { Common arterial trunk } \\
\text { Transposition of great vessels } \\
\text { Cardiomyopathy } \\
\text { Tumour } \\
\text { Other }\end{array}$ & $\begin{array}{l}3 \\
2 \\
4 \\
4 \\
6 \\
0 \\
8 \\
1 \\
1 \\
2 \\
3 \\
2 \\
0 \\
8 \\
1 \\
0 \\
0 \\
6 \\
4 \\
3\end{array}$ & $\begin{array}{r}11 \\
5 \\
2 \\
10 \\
5 \\
2 \\
11 \\
1 \\
3 \\
5 \\
2 \\
0 \\
11 \\
9 \\
1 \\
0 \\
2 \\
0 \\
7\end{array}$ & $\begin{array}{l}1 \\
1 \\
0 \\
1 \\
4 \\
0 \\
2 \\
4 \\
2 \\
3 \\
1 \\
0 \\
4 \\
1 \\
3 \\
0 \\
0 \\
0 \\
4\end{array}$ & $\begin{array}{l}0 \\
0 \\
0 \\
0 \\
3 \\
0 \\
3 \\
1 \\
2 \\
3 \\
0 \\
4 \\
9 \\
8 \\
0 \\
3 \\
5 \\
1 \\
5\end{array}$ \\
\hline
\end{tabular}

nosis at presentation, poor growth of the left ventricle, aorta, and mitral valve was observed in sequential studies so that as gestational age advanced the echocardiographic features became those of a hypoplastic left heart. There were nine fetuses with an isolated ventricular septal defect who died in the neonatal period but these all had an associated extracardiac anomaly.

\section{Discussion}

It has been observed in many forms of congenital anomaly that prenatal diagnosis detects the most severe end of the range of disease and is therefore associated with a poor outcome. ${ }^{3}$ This is also true for congenital heart disease. Cases referred for fetal echocardiography are specially selected and therefore produce a different range of disease than that seen postnatally. ${ }^{4}$ The majority of cases in our series were referred because a cardiac abnormality was suspected on a routine obstetric ultrasound scan on examination of the four chamber view. ${ }^{5}$ Thus, the more gross types of cardiac defect are seen and referred for further evaluation as a result of the four chamber screening programme. However, a number of patients were referred because of the detection of a non-cardiac structural abnormality $(14.5 \%)$ or the presence of fetal hydrops $(9 \cdot 5 \%)$. Thus those with associated non-cardiac abnormalities are also being specially selected for referral.

The incidence of associated anomalies, in particular the karyotype anomalies, is higher in this series than expected. Chromosomal abnormali- ties in association with congenital heart disease have been reported to occur in about $12-13 \%$ of cases in postnatal series. ${ }^{6}$ The overall incidence in our series of 222 cases was nearly $19 \%$. This was particularly high in the group resulting in an intrauterine or neonatal death $(21 \%$ and $24 \%$ respectively). The incidence in cases that are still alive or in those that died after the neonatal period, however, is similar to that reported postnatally (11\% and $13 \%$ respectively). The chromosomal anomaly present in all the survivors is trisomy 21 . The association between certain types of cardiac malformation and karyotype abnormalities has been previously described. ${ }^{7-9}$ Atrioventricular septal defects are commonly associated with trisomy 21 and malalignment ventricular septal defects with trisomy 18. Many unexpected associations have been encountered in the prenatal range of congenital heart disease, however, so that it is an important part of management of all continuing pregnancies to obtain a fetal karyotype.

Cardiac malformations are generally thought to be well tolerated by the fetus yet in this series of 222 cases, $13 \%$ had evidence of intrauterine cardiac failure at presentation. Some of these had an associated extracardiac anomaly, which could account for the hydrops but two thirds of cases did not. In our series, only one of the cases that had fetal hydrops and congenital heart disease is still alive.

Most forms of major cardiac malformations have been diagnosed in utero. In some cases the initial diagnosis indicates a poor prognosis. However, progression of the cardiac lesion with advancing gestational age can occur, which can 
alter the prognosis in cases that may initially appear less severe. For example, valvular stenosis can develop during fetal life and this can progress to valvular atresia by term. Valvular incompetence can become more severe as commonly occurred in cases of tricuspid valve dysplasia and Ebstein's anomaly in our series. Reduced growth of cardiac structures during pregnancy can result in a different diagnosis at term compared with findings at an earlier gestation. This has been observed, for example, in cases of critical aortic stenosis progressing to the hypoplastic left heart syndrome and has been previously reported. ${ }^{10}$ It can therefore be difficult to predict accurately the outcome of some forms of heart disease when seen early in pregnancy.

In conclusion, there are several factors influencing the outcome of congenital heart disease diagnosed prenatally. There is a high incidence of associated anomalies, which includes extracardiac structural anomalies, chromosomal anomalies, and intrauterine cardiac failure. It is therefore important to look for these in all cases. Severe cases are selected for fetal echocardiography as a result of the four chamber screening programme but even in less severe cases, progression of disease can occur in fetal life. This emphasises that the range of heart disease seen prenatally is different from that seen postnatally and this is reflected in the outcome of cases diagnosed in utero. Those involved in counselling in early pregnancy must be aware of the additional prenatal factors and allow for them in making predictions of outcome. Thus the paediatric cardiologist faced with a fetus of 18 weeks' gestation with a particular type of congenital heart disease must consider several aspects before counselling the parents. Firstly, are there extracardiac or chromosomal anomalies present? Secondly, is intrauterine cardiac failure present or is it likely to develop? Thirdly, is there potential for evolution of the defect into a more severe form of disease? Fourthly, are there features of the defect that may not be detectable in early pregnancy but which will influence such factors as operability? Only when all these factors have been taken into consideration, or eliminated where possible, should a prognosis be offered.

The authors are supported by the British Heart Foundation.

1 Allan LD, Crawford DC, Anderson RH, Tynan MJ. Echocardiographic and anatomical correlations in fetal con genital heart disease. $\mathrm{Br}$ Heart $\mathcal{F}$ 1984;52:542-8.

2 Kleinman CS, Hobbins JC, Jaffe CC, Lynch DC, Talner NS Echocardiographic studies of the human fetus: prenatal diagnosis of congenital heart disease and cardiac dysrhythmias. Pediatrics 1980;65:1059-67.

3 Benacerraf BR, Adzick NS. Fetal diaphragmatic hernia: ultrasound diagnosis and clinical outcome in 19 cases. $A m \mathcal{F}$ Obstet Gynecol 1987;156:573-6.

4 Allan LD, Crawford DC, Anderson RH, Tynan MJ. Spectrum of congenital heart disease detected echocardiographically in prenatal life. $\mathrm{Br}$ Heart $\mathcal{f}$ 1985;54:523-6.

5 Allan LD, Crawford DC, Chita SK, Tynan MJ. Prenat screening for congenital heart disease. $B M \mathcal{F}$ 1986;292: 1717-9.

6 Ferencz C, Neill CA, Boughman JA, Rubin JD, Brenner JI, Perry LW. Congenital cardiovascular malformations associated with chromosome abnormalities: an epidemiologic ated with chromosome abnormalite

7 Machado MLV, Crawford DC, Anderson RH, Allan LD Atrioventricular septal defect in prenatal life. Br Heart $\dot{f}$ 1988;59:352-5.

8 Lacro RV, Lyons Jones K, Benirschke K. Coarctation of the aorta in Turner syndrome: a pathological study of fetuses with nuchal cystic hygromas, hydrops fetalis and female genitalia. Pediatrics 1988;81:445-51.

9 Waldimiroff JW, Stewart PA, Reuss A, Sachs ES. Cardiac and extracardiac anomalies as indicators for trisomies 13 and 18: a prenatal ultrasound study. Prenat Diagn 1989;9: $515-20$.

10 Allan LD, Sharland GK, Tynan MJ. The natural history of the hypoplastic left heart syndrome. Int $\mathcal{F}$ Cardiol 1989;25: 341-3. 